\title{
Comment on Poole et al (2022) review on oxygen flux from capillaries to mitochondria
}

\author{
Guido Ferretti ${ }^{1,2}$ (1)
}

Received: 8 December 2021 / Accepted: 9 December 2021 / Published online: 18 December 2021

(c) The Author(s), under exclusive licence to Springer-Verlag GmbH Germany, part of Springer Nature 2021

The review by David Poole, Timothy Musch and Trenton Colburn on oxygen flow from capillary to mitochondria, which is published in the present issue of this Journal (Poole et al. 2022), deserves highest consideration. It is part of a topical series on "A Century of Exercise Physiology", in concomitance with the centennial of the Nobel Prize award to Archibald Vivian Hill and Otto Fritz Meyerhof. This review celebrates another giant of twentieth century physiology, Nobel Prize winner, August Krogh, who published his masterpiece on the anatomy and physiology of capillaries exactly 100 years ago (Krogh 1922).

The review is very stimulating, rich and well thought. Its structure is analytic, encompassing all the steps between the red blood cell and the muscle fibre mitochondria. Each is discussed in detail, following the peripheral oxygen pathway, which is rigorously analyzed step by step both structurally and functionally. Their description of oxygen diffusion outside the capillary goes beyond August Krogh's paradigm of a homogeneous diffusion process through straight capillaries (Krogh 1922). Table 1 of their review is a nice synoptic summary of the proposed change of paradigm, in which the traditional and the contemporary visions of oxygen flow to tissues are compared. Some sections on cellular mechanisms are beautiful examples of clarity, logical thinking and sequential organization of the information. Assumptions and limitations are explicitly presented.

Heterogeneity is the keyword of this review. This concept was absent in Krogh's thinking, but was present in Johannes Piiper's thinking, when he established his model of

Communicated by Westerterp/Westerblad.

Guido Ferretti

guido.ferretti@unige.ch

1 Dipartimento di Medicina Molecolare e Traslazionale, Università di Brescia, Brescia, Italy

2 Département d'Anesthésiologie, Pharmacologie et Soins Intensifs, Université de Genève, Geneva, Switzerland peripheral gas exchange (Piiper et al. 1984). Piiper assumed an average peripheral capillary-tissue membrane, allowing circumvention of the effects of heterogeneous peripheral gas exchange. Notwithstanding this assumption, Piiper (2000) discussed the possible effects of heterogeneities in perfusion/ diffusion. He concluded that they decrease the efficiency of oxygen transfer. Overlooking heterogeneity would lead to an overestimation of the role of diffusion limitation. The further advancement of knowledge subsumed by Poole et al. (2022), puts under a better focus the causes of heterogeneity. The process started with Hans Hoppeler's notions of uneven distribution of mitochondria in muscle fibres (Hoppeler et al. 1985, 1987) and of capillary tortuosity (Mathieu-Costello et al. 1989), and is still evolving, thanks largely to the work of Poole and Musch.

Piiper's approach can be translated at the whole body level by setting arterial and mixed venous pressions ( and $\mathrm{P}_{\bar{\nu}} \mathrm{O}_{2}$, respectively) as the oxygen partial pressures at the two extremes of a meta-capillary representing overall gas exchange. This requires some degree of abstraction, which however, is necessary to provide a representation of the interaction between diffusion and perfusion in pulmonary and peripheral gas exchange at higher levels of organization than the cellular and subcellular ones. Peter Wagner, who has a clear vision of the consequences of operating at different levels of organization, constructed a diagram describing the relationship between oxygen flow and venous oxygen pressure (Wagner's diagram). He put $P_{\bar{v}} O_{2}$ on the $x$-axis, suggesting a whole-body application of his diagram. In fact it was designed to interpret maximal oxygen consumption limitation (Roca et al. 1989; Wagner 1993), yet it is a universal tool, theoretically applicable from the whole body level to the single capillary.

In Wagner's diagram, the diffusive line has a constant slope. Ferretti (2014) called its slope Wagner's constant $\left(K_{\mathrm{w}}\right)$. It has the dimension of a conductance, proportional to the tissue diffusing capacity for oxygen $\left(D_{t} O_{2}\right)$. This shows that Wagner, as Piiper, was inspired by Krogh's vision of 
peripheral gas exchange. When we move on a lower level of organization, a linear diffusive line (constant $K_{\mathrm{w}}$ ) carries along the implicit assumption of a Krogh cylinder model of peripheral gas exchange (top of Fig. 3 of Poole's review). Poole's contemporary vision of peripheral gas exchange (bottom of their Fig. 3), with sudden discrete drops of oxygen partial pressure at specific high-resistance sites along the pathway, is incompatible with a linear diffusive line, unless we consider a mean conductance to oxygen flow in peripheral tissues: this would be the same assumption made by Piiper et al. (1984). Poole et al (2022) reproduce it as their Fig. 2: on the $x$ axis, they put a generic venous of microvascular oxygen partial pressure, and without scales. This means that: (1) their version of Wagner's diagram is conjectural; (2) they are aware of its versatility; (3) they admit an invariant $K_{\mathrm{w}}$ also at the single capillary level, whatever its value, despite heterogeneity; (4) they have a propensity to abstraction similar to Piiper's and Wagner's. In sum, they are real scientists.

Author contributions GF, only author of this manuscript, conceived, wrote and corrected the editorial. He selected the references and prepared the reference list. He submitted the manuscript. He apologizes for joking about a system requiring such a statement for a single-author manuscript.

\section{References}

Ferretti G (2014) Maximal oxygen consumption in healthy humans: theories and facts. Eur J Appl Physiol 114:2007-2036
Hoppeler H, Howald H, Conley K, Lindstedt SL, Claassen H, Vock P, Weibel ER (1985) Endurance training in humans: aerobic capacity and structure of skeletal muscle. J Appl Physiol 59:320-327

Hoppeler H, Hudlicka O, Uhlmann E (1987) Relationship between mitochondria and oxygen consumption in isolated cat muscles. $\mathbf{J}$ Physiol 385:661-675

Krogh A (1922) The anatomy and physiology of capillaries. Yale University Press, New Haven

Mathieu-Costello O, Hoppeler H, Weibel ER (1989) Capillary tortuosity in skeletal muscles of mammals depends on muscle contraction. J Appl Physiol 66:1436-1442

Piiper J (2000) Perfusion, diffusion and their heterogeneities limiting blood-tissue $\mathrm{O}_{2}$ transfer in muscle. Acta Physiol Scand 168:603-607

Piiper J, Meyer M, Scheid P (1984) Dual role of diffusion in tissue gas exchange: blood-tissue equilibration and diffusion shunt. Respir Physiol 56:131-144

Poole DC, Musch TI, Colburn T (2022) A century of exercise physiology: key concepts in oxygen flux from capillary to mitochondria. Eur J Appl Physiol (this issue)

Roca J, Hogan MC, Story D, Bebout DE, Haab P, Gonzalez R, Ueno O, Wagner PD (1989) Evidence for tissue diffusion limitation of in normal humans. J Appl Physiol 67:291-299

Wagner PD (1993) Algebraic analysis of the determinants of $\mathrm{VO}_{2}{ }^{\max }$. Respir Physiol 93:221-237

Publisher's Note Springer Nature remains neutral with regard to jurisdictional claims in published maps and institutional affiliations. 